Landslides (2019) 16:1623-1628 DOI 10.1007/s10346-019-01242-3 Received: 8 July 2019

Accepted: 9 July 2019

Published online: 30 July 2019

(c) Springer-Verlag GmbH Germany

part of Springer Nature 2019
K. Sassa

\section{Journal Landslides, the International Consortium on Landslides, and the Kyoto Landslide Commitment 2020}

Introduction

The International Consortium on Landslides (ICL) organized the first session of the Board of Representatives (BOR) of ICL at UNESCO headquarters on 19-21 November 2002. The session established the International Programme on Landslides (IPL) as its scientific program aiming to provide international authorization and advice to the projects proposed by the ICL members. The Board decided to establish the official journal "Landslides" of the ICL as the initial coordinating project (IPL-C10o) of the IPL.

Landslides is the most important activity of the ICL for the progress of Landslide Science which will constitute the background of the ICL and its program IPL. Landslides has been developed by intellectual, practical, and financial supports from all ICL members and supports from landslide-related United Nations organizations and other global stakeholders who are willing to promote the landslide disaster risk reduction. Landslide disaster risk is increasing due to changing climate and global warming, and the progress of mountains, coastal, and urban development in many countries of the world. Landslide disaster risk reduction is one of the pressing global issues.

The ISDR-ICL Sendai Partnerships (now called as the Sendai Landslide Partnerships) 2015-2025 was established in Sendai in March 2015 (Sassa 2015). To develop the partnerships for a longterm and stable framework to 2025, 2030, and beyond, the Kyoto Landslide Commitment 2020 (KLC2020) was proposed in May 2017 during the Fourth World Landslide Forum held in Ljubljana, Slovenia (Sassa 2019). Landslides is expected to take a core role in the promotion of the $\mathrm{KLC}_{2020}$ for landslide disaster risk reduction. The ICL invites all relevant organizations and individuals to support this planned voluntary contribution (KLC2020) to the Sendai Landslide Partnerships 2015-2025, the Sendai Framework for Disaster Risk Reduction 2015-2030, the 2030 Agenda Sustainable Development Goals, the New Urban Agenda, and the Paris Climate Agreement.

Landslides: journal of the International Consortium on Landslides Phenomena of landslides-downslope movements are studied by geologists, geomorphologists, civil engineers, mining engineers, agricultural and forest researchers, urban and city planning officers, and others. Technical terms and basic sciences are different for those landslide-related fields. Until the establishment of the journal Landslides, there was no international journal on landslides which was vitally necessary for the development of landslide science as an independent scientific field. Full-color photos of Landslides are common information which are understandable even without technical terms, specifically for all fields of scientists, engineers, officers, and policymakers.
The Japan Landslide Society published three color (the final issue was full color)-printed newsletter Landslide News from 1987 to 2003 for 15 years. Five thousand copies were printed and 2000 copies of Landslide News were distributed to world landslide researchers outside of Japan free of charge. At that point, we planned to publish full-color journal on landslides as one-step ahead of the Landslide News. The ICL negotiated with several international publishers on the possible publication of a fullcolor scientific journal from November 2002 (the first session of the Board of Representatives of the ICL) to March 2003. As a result of negotiation, the ICL reached the agreement to publish the world's first scientific full-color journal Landslides with Springer Verlag at Heidelberg, Germany. The first volume was published in 2004 with 4 issues/year and 323 pages/year. The journal had an impact factor of 0.986 in 2007 . It moved to bimonthly journal in 2013 with 851 pages/year and the impact factor also increased to 2.814. The publication frequency of the journal has then moved to monthly in 2018 with 2524 pages/year and the impact factor further increased to 4.252 (Fig. 1). A total of 1312 landslide researchers have been registered as reviewers of Landslides, and 151 researchers have been registered as editors of Landslides. A total of 108 editors and 333 reviewers have voluntarily worked for the edition and reviews of Vol. 15 of Landslides 2018 (Editorial Board of Landsides 2019).

\section{Categories of articles for Landslides}

Landslides has different categories of articles with specific objectives

1. Original papers (less than 12 pages): original research and investigation results. These contributions require the highest degree of originality.

2. Review papers (less than 12 pages): review of current research and development of technology in a thematic area of landslide studies.

3. Recent Landslides (2-10 pages): reports of recent landslides including location. Information of new landslides in various region of the world are important for the landslide community.

4. Technical Note (4-8 pages): research notes, reviews notes, case studies, progress of technology, and best practice in monitoring, testing, investigation, and mitigation measures.

5. IPL/WCOE Activities (4-8 pages): progress of IPL projects, World Centers of Excellence on Landslide Risk Reduction (WCoEs), and other IPL activities.

6. News/Kyoto Commitment (less than 4 pages): news, reports, announcement of meetings, and all types of articles promoting the Kyoto Landslide Commitment 2020. 


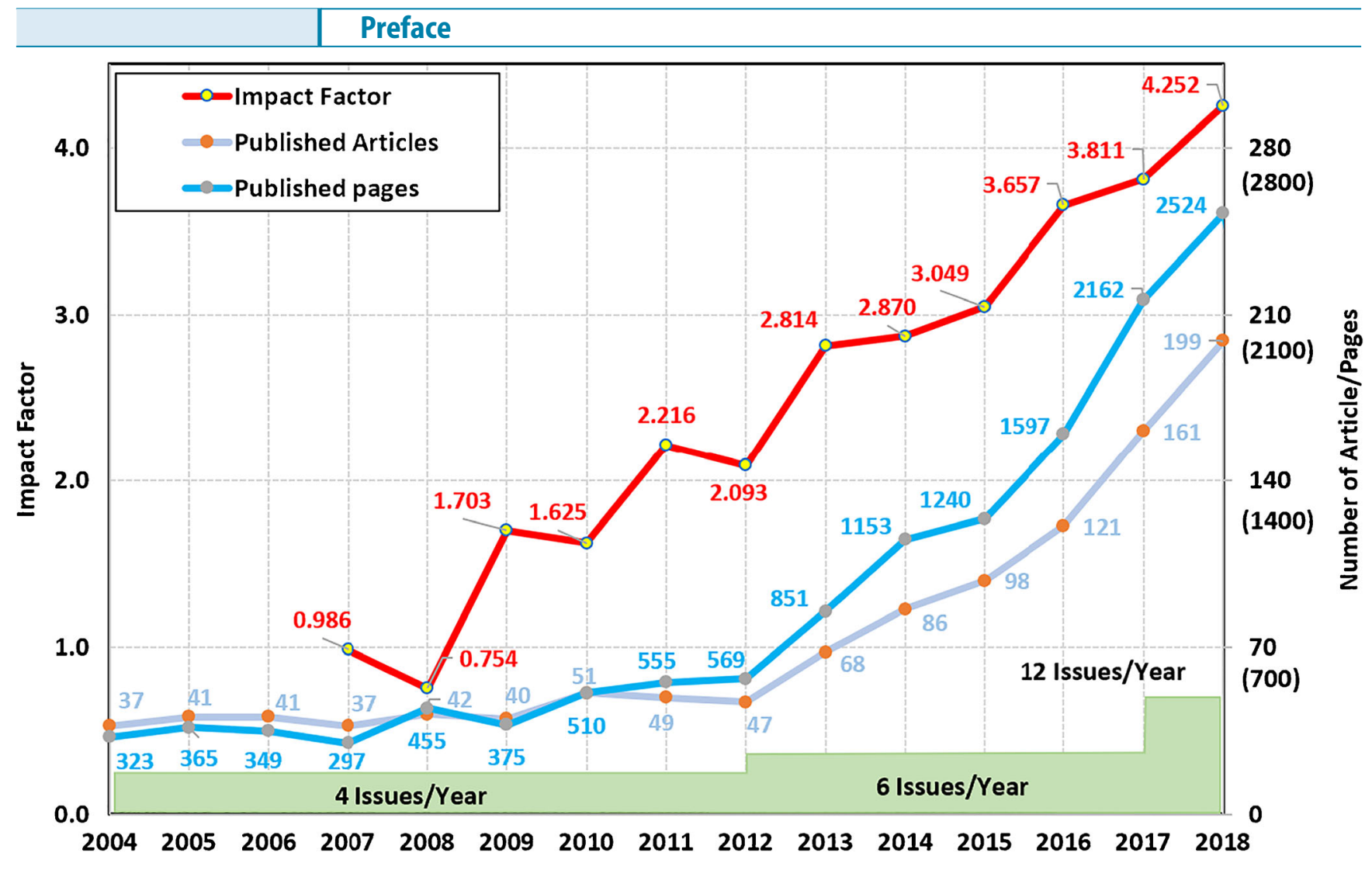

Fig. 1 Page number, article number, and impact factor of Landslides from its establishment in 2018

The current target of the ICL after the establishment of the journal Landslides is the ongoing establishment of long-term and stable framework for landslide disaster risk reduction:

Kyoto 2020 Commitment for global promotion of understanding and reducing landslide disaster risk - A commitment to the ISDR-ICL Sendai Partnerships 2015-2025, the Sendai Framework for Disaster Risk Reduction 2015-2030, the 2030 Agenda Sustainable Development Goals, the New Urban Agenda, and the Paris Climate Agreement (Kyoto Landslide Commitment 2020: $\mathrm{KLC2020).}$

In order to promote the Kyoto Landslide Commitment 2020, the category of News/Kyoto Commitment was created in 2018 to be a common platform for all partners of KLC2020. This category aims to publish news, information, and activities of all partners of KLC2020. The list of recent articles from Vol. 15 (7) in 2018 to Vol. 16 (7) in 2019 is as follows.

\section{Articles of News/Kyoto Commitment}

The Global Promotion Committee of the International Programme on Landslides (IPL) and IPL World Centre. Landslides 15(7): 1453-1455.

Announcement of 2018 ICL-IPL Conference in Kyoto, Japan-Planning of the Fifth World Landslide Forum (WLF5) and the Kyoto 2020 Commitment (KC2020). Landslides 15(7): 1449-1451.

Huang R, Fan X, Xu Q et al. (2018) The iRALL Doctoral School 2018: advanced studies on large landslides on the 1oth anniversary of the Wenchuan earthquake. Landslides 15(9): 1901-1903.
Sassa K, Canuti P, Takara K et al. (2018) In memoriam-Hiroshi Fukuoka (1961-2018). Landslides 15(9): 1905-1906.

Sassa K \& Konagai K (2018) Annex of establishment of ICLJapan for the Kyoto 2020 Commitment. Landslides Vol.15(11): 2315-2319.

Yamagishi H \& Yamazaki F (2018) Landslides by the 2018 Hokkaido Iburi-Tobu Earthquake on September 6. Landslides 15(12): 2521-2524.

Hirota K, Konagai K, Sassa K. et al. (2019) Landslides triggered by the West Japan Heavy Rain of July 2018, and geological and geomorphological feature of soaked mountain slopes. Landslides 16(1): 189-194.

Sassa S \& Takagawa T (2019) Liquefied gravity flow-induced tsunami: first evidence and comparison from the 2018 Indonesia Sulawesi earthquake and tsunami disasters. Landslides 16(1): 195-200.

Sassa K et al. (2019) Invited and accepted speakers of the Fifth World Landslide Forum in Kyoto, 2020. Landslides 16(2): 431-446.

Liang $\mathrm{G}$ et al. Two huge landslides that took place in quick succession within a month at the same location of Jinsha River. Landslides 16(5): 1059-1062.

Cui $\mathrm{P}$ et al. Announcement of 2019 International Conference on Silk-roads Disaster Risk Reduction and Sustainable Development. Landslides 16(6): 1253-1256.

Cascini L et al. (2019) LARAM School 2019: the yearly doctoral school on "LAndslide Risk Assessment and Mitigation". Landslides 16(7): 1419-1421.

Sassa K et al. (2019) Registered speakers in the Fifth World Landslide Forum. DOI https://doi.org/10.1007/s10346-019-01214-7 
Tofani V et al. (2019) EGU 2019 Sergey Soloviev Medal Lecture. Landslides, DOI https://doi.org/10.1007/s10346-019-01232-5

Tofani V (2019) Department of Earth Sciences, University of Florence. Landslides, Move on production.

Mikos M (2019) Faculty of Civil and Geodetic Engineering, University of Ljubljana. Landslides, Move on production.

Zekan S (2019) 4th Regional Symposium on Landslides in the Adriatic-Balkan Region-Sarajevo, Bosnia and Herzegovina. Landslides, Move on production.

Wong A et al. (2019) Landslide Risk Management in Hong Kong-Experience in the Past and Planning for the Future. Landslides, Accepted.

ICL members have published their activities of IPL projects and WCOE contributing to the Landslide Sendai Partnerships 2015-2025 from Vol. 15 (7) in 2018 to Vol. 16 (7) in 2019 as follows.

\section{IPL/WCOE activities}

Alcántara-Ayala I et al. (2018) Landslide disaster risk awareness in Mexico: community access to mapping at local scale. Landslides 15 (8): 1691-1704.

Igwe $\mathrm{O}$ (2018) The characteristics and mechanisms of the recent catastrophic landslides in Africa under IPL and WCoE projects. Landslides 15 (12): 2509-2519.

Guo Y et al. (2019) Seminar on "Engineering and environmental geology in the permafrost region along the Sino-RussianMongolian Economic Corridor under the background of climate change" and the Annual Academic Conference of 2018 of ICLCRLN and the Cold Region Landslide Research of IPL-WCoE held in Harbin. Landslides 16 (4): 857-861.

Strom A (2019) 2019 International Summer School on Rockslides and Related Phenomena in the Kokomeren River valley (Kyrgyzstan). Landslides 16 (5): 1055-1057.

Guzzetti F \& Gariano S L (2019) Activities of the Research Institute for Geo-Hydrological Protection, of the Italian National Research Council, World Centre of Excellence on landslide risk. Landslides 16 (7): 1415-1418.

\section{The International Consortium on Landslides}

All International Consortium on Landslides (ICL) members have contributed to intellectual, practical, and financial aspects for the edition and publication of Landslides, and all ICL supporting organizations have contributed to Landslides in intellectual and practical aspects of publication of Landslides through provision of advices, information, convenience, and facilities. Contributions from all ICL members and ICL supporting organizations are appreciated for the progress of Landslides.

The history and information of the ICL and the International Programme on Landslides (IPL) including IPL projects and the World Centres of Excellence on Landslide Disaster Reduction (WCOEs), ICL supporting organizations, partners of the Sendai Landslide Partnerships are introduced in Part I ISDR-ICL Sendai Partnerships 2015-2025 (page 3-226), Part II International Programme on Landslides (IPL) (page 229-484) of the Volume 1 ISDR-ICL Sendai Partnerships 2015-2025 of "Advancing Culture of Living with Landslides" at the opportunity of the Fourth World Landslide Forum in Ljubljana, Slovenia, in 2017 (Sassa et al. 2017). This book is published both in printed version and the free access digital version (open access book ISBN 978-3319-59469-9 (https://www.springer.com/gp/ book/9783319535005).

\section{ICL supporting organizations}

United Nations Educational, Scientific and Cultural Organization (UNESCO), World Meteorological Organization (WMO), Food and Agriculture Organization of the United Nations (FAO), United Nations Office for Disaster Risk Reduction (UNDRR), United Nations University (UNU), International Science Council (ISC), World Federation of Engineering Organizations (WFEO), International Union of Geological Sciences (IUGS), International Union of Geodesy and Geophysics (IUGG), the Government of Japan (Cabinet Office; Ministry of Education, Sports, Science and Technology; Ministry of Agriculture, Forestry and Fisheries; Ministry of Land, Infrastructure and Tourism), and Kyoto University are current ICL supporting organizations.

The ICL consists of full members, associates, and also supporters. The total number of members is 99 from 37 countries/ regions. Figure $2 \mathrm{a}$ and $\mathrm{b}$ presents the areal distribution of members and the number of each country/region.

Figure 2 a presents global representation of ICL members. Figure $2 \mathrm{~b}$ shows ICL members from each country/region.

The number of supporters in Japan is the largest. Most supporters in Japan are companies and organizations which supported the publication of three color-printed international newsletter Landslide News published by the Japan Landslide Society from 1987 to 2003 for 15 years and also publication of Landslides from 2004 to present for 15 years. Italy has seven full members, six associates, and one supporter; China has nine full members and one associate. Korea has five full members, and there are four full members from Indonesia.

All of ICL full members, associated members, and supporters have contributed to the publication of Journal Landslides from intellectual, practical, and financial aspects and the implementation of the Sendai Landslide Partnerships 20152025, and contribution to the Kyoto Landslide Commitment 2020 is also expected. The list of members in June 2019 is presented below with thanks.

\section{ICL full members (with voting right and proposal right of IPL project and WCOE)}

ICL membership fee (3000 USD) + IPL supporting fund (2000 USD) (ICL supporting organization)

- Geotechnical Engineering Office, Hong Kong Special Administrative Region, China

- University of Firenze, Earth Sciences Department, Italy

- Korea Institute of Geoscience and Mineral Resources (KIGAM)

- University of Ljubljana, Faculty of Civil and Geodetic Engineering (ULFGG), Slovenia

ICL membership fee proportional to GNIPC (500-3000 USD)

- Albania Geological Survey 
a

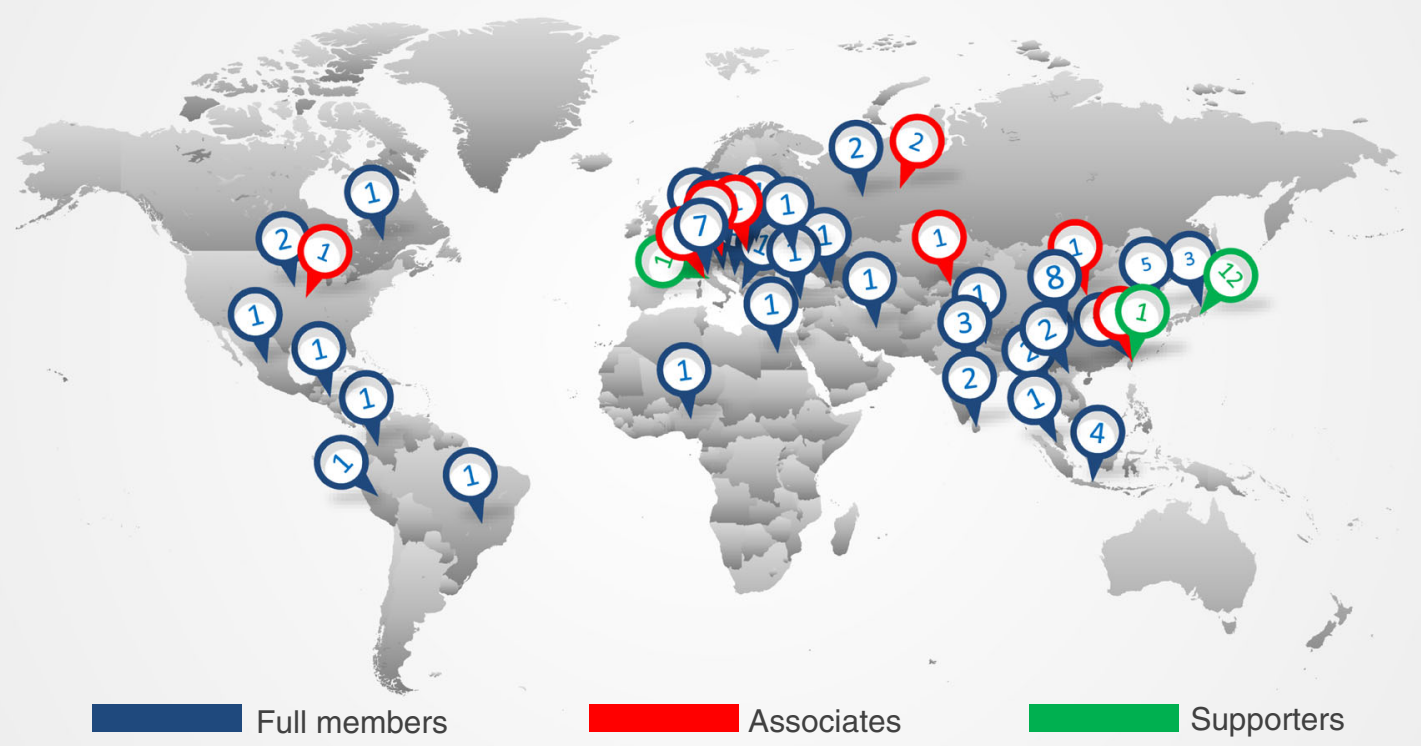

b

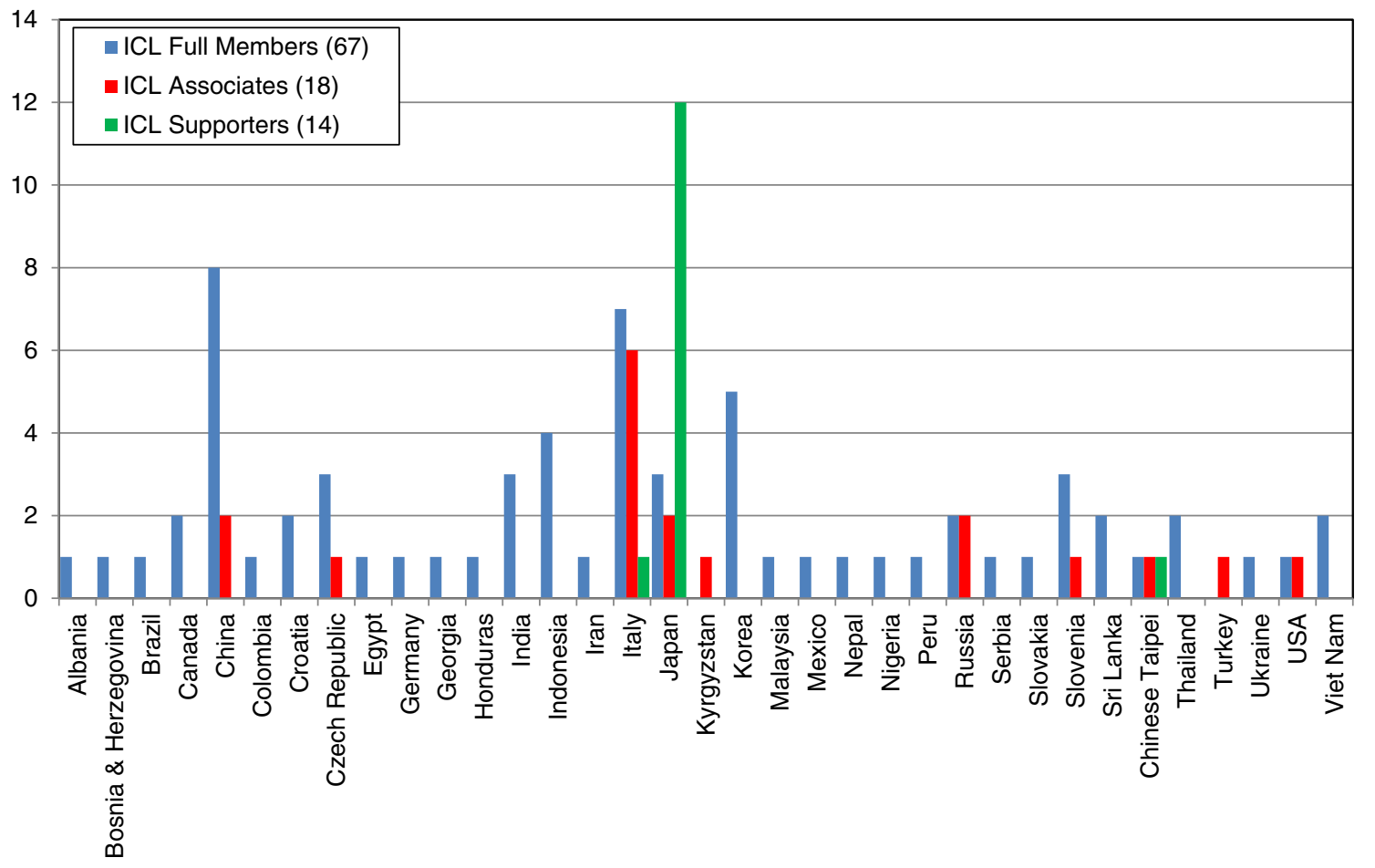

Fig. 2 a Location and $\mathbf{b}$ the number of ICL members in each country/region 
- The Geotechnical Society of Bosnia and Herzegovina

- Center for Scientific Support in Disasters - Federal University of Parana, Brazil

- Geological Survey of Canada

- University of Alberta, Canada

- Northeast Forestry University, Institute of Cold Regions Science and Engineering, China

- China University of Geosciences

- China Geological Survey

- Chinese Academy of Sciences, Institute of Mountain Hazards and Environment

- Tongji University, College of Surveying and Geo-Informatics, China

- The Hong Kong University of Science and Technology, China

- Shanghai Jiao Tong University, China

- Universidad Nacional de Colombia

- Croatian Landslide Group (Faculty of Civil Engineering, University of Rijeka and Faculty of Mining, Geology and Petroleum Engineering, University of Zagreb)

- City of Zagreb, Emergency Management Office, Croatia

- Charles University, Faculty of Science, Czech Republic

- Institute of Rock Structure and Mechanics, Department of Engineering Geology, Czech Republic

- Brown Coal Research Institute, Inc. Czech Republic

- Cairo University, Egypt

- Technische Universitat Darmstadt, Institute and Laboratory of Geotechnics, Germany

- National Environmental Agency, Department of Geology, Georgia

- Universidad Nacional Autonoma de Honduras (UNAH), Honduras

- Amrita Vishwa Vidyapeetham, Amrita University

- Vellore Institute of Technology, India

- National Institute of Disaster Management, India

- Agency for Meteorology, Climatology, and Geophysics of the Republic of Indonesia (BMKG Indonesia)

- University of Gadjah Mada, Center for Disaster Mitigation and Technological Innovation (GAMA-InaTEK), Indonesia

- Parahyangan Catholic University, Indonesia / Research

- Center for Geotechnology, Indonesian Institute of Sciences, Indonesia

- Building \& Housing Research Center, Iran

- Italian Institute for Environmental Protection and Research (ISPRA) - Dept. Geological Survey, Italy

- University of Calabria, DIMES, CAMILAB, Italy

- Istituto de Ricerca per la Protezione Idrogeologica (IRPI), CNR, Italy

- DIA-Universita degli Studi di Parma, Italy

- University of Torino, Dept of Earth Science, Italy

- Centro di Ricerca CERI - Sapienza Universita di Roma, Italy

- Kyoto University, Disaster Prevention Research Institute, Japan

- Japan Landslide Society, Japan

- Korean Society of Forest Engineering

- National Institute of Forest Science, Korea

- Korea Infrastructure Safety \& Technology Corporation

- Korea Institute of Civil Engineering and Building Technology

- Slope Engineering Branch, Public Works Department of Malaysia
- Institute of Geography, National Autonomous University of Mexico (UNAM)

- International Centre for Integrated Mountain Development (ICIMOD), Nepal

- University of Nigeria, Department of Geology, Nigeria

- Grudec Ayar, Peru

- Moscow State University, Department of Engineering and Ecological Geology, Russia

- JSC “Hydroproject Institute", Russia

- University of Belgrade, Faculty of Mining and Geology, Serbia

- Comenius University, Faculty of Natural Sciences, Department of Engineering Geology, Slovakia

- Geological Survey of Slovenia

- University of Ljubljana, Faculty of Natural Sciences and Engineering (ULNTF), Slovenia

- Central Engineering Consultancy Bureau (CECB), Sri Lanka

- National Building Research Organization, Sri Lanka

- Landslide group in National Central University from Graduate Institute of Applied Geology, Department of Civil Engineering, Center for Environmental Studies, Chinese Taipei

- Asian Disaster Preparedness Center, Thailand

- Ministry of Agriculture and Cooperative, Land Development Department, Thailand

- Institute of Telecommunication and Global Information Space, Ukraine

- California State University, Fullerton, Department of Civil and Environmental Engineering and Tribhuvan University, Institute of Engineering, USA and Nepal

- Institute of Transport Science and Technology, Vietnam

- Vietnam Institute of Geosciences and Mineral Resources (VIGMR)

ICL Society member

- International Consortium on Geo-disaster Reduction, Japan

\section{ICL associates (20\% of ICL membership fee, 100-600 USD)}

- State Key Laboratory of Geohazard Prevention and Geoenvironment Protection (Chengdu University of Technology), China

- Huazhong University of Science and Technology

- Czech Geological Survey, Czech Republic

- Department of Earth and Environmental Sciences, University Aldo Moro, Bari, Italy

- University of Bologna - BIGEA Department, Italy

- Department of Engineering and Geology University of ChietiPescara, Italy

- Department of Earth and Environmental Sciences - University of Pavia, Italy

- University of Sannio - Department of Sciences and Technologies, Italy

- Geotechnical Engineering Group (GEG), University of Salerno, Italy

- Niigata University, Research Institute for Natural Hazards and Disaster Recovery, Japan

- Ehime University Center for Disaster Management Informatics Research, Japan 
- Tian-Shan Geological Society, Kyrgyzstan

- Institute of Environmental Geoscience RAS (IEG RAS), Russia

- Russian State Geological Prospecting University n.a. Sergo Ordzhonikidze (MGRI-RSGPU)

- TEMPOS, environmental civil engineering Ltd., Slovenia

- National Taiwan University, Department of Civil Engineering, Chinese Taipei

- Middle East Technical University (METU), Turkey

- North Dakota State University, USA

\section{ICL supporters}

ICL supporters (2000 USD)

- Marui \& Co., Ltd., Osaka, Japan

- Okuyama Boring Co., Ltd., Yokote, Japan

ICL supporters (1000 USD)

- Central Japan Railway Company, Nagoya, Japan

- IDS GeoRadar s.r.l., Pisa, Italy

- GODAI Development Corp., Kanazawa, Japan

- Japan Conservation Engineers \& Co., Ltd., Tokyo

- Kokusai Kogyo Co., Ltd., Tokyo, Japan

- NIPPON KOEI Co., Ltd., Tokyo, Japan
- Ohta Geo-Research Co., Ltd., Nishinomiya, Japan

- OSASI Technos Inc., Kochi, Japan

- OYO Corporation, Tokyo, Japan

- Sabo Technical Center, Tokyo, Japan

- Sakata Denki Co., Ltd., Tokyo, Japan

- Sinotech Engineering Consultants, Inc., Chinese Taipei
References

Editorial Board of Landslides (2019) Editors and reviewers working for landslides in 2018. Landslides 16(4):863-874

Sassa K (2015) ISDR-ICL Sendai partnerships 2015-2025 for global promotion of understanding and reducing landslide. Landslides 12(4):631-640

Sassa K (2019) The fifth World Landslide Forum and the final draft of the Kyoto 2020 Commitment. Landslides 16(2):201-211

Sassa K, Mikos M, Yin Y (editors) (2017) Advancing Culture of Living with Landslides, Vol.1 ISDR-ICL Sendai Partnerships 2015-2025. Springer, Open access book ISBN 9783-319-59469-9 (https://www.springer.com/gp/book/9783319535005)

K. Sassa $(\square)$

International Consortium on Landslides (ICL),

Kyoto, Japan

Email: secretariat@iclhq.org 